\title{
Short-Chain Acyl-Coenzyme A Dehydrogenase Deficiency in Mice
}

\author{
PHILIP A. WOOD, BRAD A. AMENDT, WILLIAM J. RHEAD, DAVID S. MILLINGTON, \\ FUMIO INOUE, AND DAWNA ARMSTRONG

\begin{abstract}
Institute for Molecular Genetics [P.A.W.] and Department of Pathology [D.A.], Baylor College of Medicine,
\end{abstract} \\ Houston, Texas 77030, Department of Pediatrics, University of Iowa, Iowa City, Iowa 52242 [B.A.A., W.J.R.], \\ and Department of Pediatrics, Duke University Medical Center, Durham, North Carolina 27710 [D.S.M., F.I.]
}

\begin{abstract}
A murine model for short-chain acyl-coenzyme A dehydrogenase (SCAD) deficiency has been identified and characterized in BALB/cByJ mice. These mice have undetectable SCAD activity, severe organic aciduria; excreting ethylmalonic and methylsuccinic acids and $N$ butyrylglycine, and develop a fatty liver upon fasting or dietary fat challenge. The mutant mice develop hypoglycemia after an 18-h fast, and have elevated urinary and muscle butyrylcarnitine concentrations. Most of these findings parallel those of human disorders associated with SCAD deficiency and other $\beta$-oxidation defects. This mouse model presents important opportunities to investigate the biology of mammalian fatty acid metabolism and the related human diseases. (Pediatr Res 25:38-43, 1989)
\end{abstract}

\section{Abbreviations}

SCAD, short-chain acyl-CoA dehydrogenase MCAD, medium-chain acyl-CoA dehydrogenase MCT, medium-chain triglycerides

Deficiency of SCAD has been described recently in humans (1-4). The most severe form of this disorder is characterized by patients with episodes of metabolic acidosis, nonketotic hypoglycemia, and short-chain dicarboxylic aciduria. The clinical outcomes range from normalcy to unexpected death in homozygotes. Lately, sudden infant death syndrome and Reye's-like syndrome have been linked to defects in $\beta$-oxidation of fatty acids (5-7). Other recent studies have demonstrated that a secondary carnitine deficiency associated with the organic acidemia appears involved in the pathogenesis of the episodic events of these disorders $(1,4,8)$. Overall, these diseases appear complex.

We have a program to screen mice for inherited metabolic diseases (9) to develop models for investigating the pathogenesis and treatment of these disorders. In the course of screening mutant mice for organic acidurias using gas chromatographymass spectrometry, we discovered a subline of BALB/c mice $(\mathrm{BALB} / \mathrm{cByJ})$ that excreted unusually large concentrations of ethylmalonic and methylsuccinic acids and $N$-butyrylglycine. Butyryl-CoA dehydrogenase activity and electrophoretic mobility are used as a genetic marker for the Bcd-1 locus on mouse

Received August 4, 1988; accepted September 1, 1988

Correspondence Philip A. Wood, D.V.M., Ph.D., Department of Comparative Medicine, University of Alabama at Birmingham, Birmingham, AL 35294.

This work was supported by NIH Grants RR-02599 (P.A.W.) and AM 33289 and grants from the Muscular Dystrophy Association and the Brent Brees Research Fund (W.J.R.). chromosome 5 (10). Subsequently, we learned that BALB/cByJ mice were found to have no detectable butyryl-CoA dehydrogenase activity by this marker assay (10). The null allele of these mice was designated $\mathrm{Bcd}-1^{\mathrm{c}}$ and was distinctly different from the normal activity associated with the Bcd $-1^{\mathrm{b}}$ allele of $\mathrm{BALB} / \mathrm{cJ}$ or $\mathrm{BALB} / \mathrm{cBy}$ mice. To investigate the enzymatic defect and the resulting metabolic consequences, we performed a series of experiments using BALB/c By (Y) mice as controls and the BALB/ c ByJ $(J)$ mutant mice.

\section{MATERIALS AND METHODS}

Mice. BALB/cBy and BALB/cByJ mice were purchased from The Jackson Laboratory, (Bar Harbor, ME) and propagated at the Baylor College of Medicine (Houston, TX). All mice were maintained on Wayne rodent food no. 8640 (Wayne Pet Food Division, Continental Grain Co., Chicago, IL) and water ad libitum. Heterozygous mice were produced by crossing a $Y$ female with a J male.

Biochemistry. Urinary organic acids were analyzed by gas chromatography-mass spectrometry as described previously (9). Quantitative analysis of organic acids was performed by establishing standard curves of the metabolites of interest coextracted from water with the internal standard malonic acid. Urine samples were extracted and analyzed in a similar way with final quantification of the metabolites based upon the creatinine concentration of the urine, calculated from the internal standard added to the urine as described (9). Ethylmalonic, methylsuccinic, and succinic acids were obtained from Sigma Chemical Co., St. Louis, MO. Because a standard for quantification of $N$ butyrylglycine was not available, values obtained are the succinic acid molar equivalent. Serum amino acids were analyzed as described (9) and serum glucose was determined by the toluidine blue $\mathrm{O}$ method (11). (Toluidine blue $\mathrm{O}$ was obtained from Eastman Kodak, Rochester, NY.) ACyl-CoA dehydrogenase assays were performed using the dye reduction assay as described previously (3) on liver mitochondria isolated as before (12). Carnitine analysis was done using the radioenzymatic method $(13,14)$ to determine the free and acylcarnitines, and specific carnitine species were identified and quantified using fast-atom bombardment-mass spectrometry $(15,16)$.

$M C T$ challenge and fasting experiments. Two-month-old mice of both genotypes and sexes were assigned to a group to receive either MCT and fast for $10 \mathrm{~h}$ or fast only. Nonfasting urine samples were collected before treatment, and MCT was given per os at $150 \mathrm{mg} / \mathrm{kg}, 3 \times$ every $4 \mathrm{~h}$, and the final samples of urine, blood, and tissues were obtained $2 \mathrm{~h}$ after the last dose. In a different experiment, mice of each genotype were fasted for 18 $\mathrm{h}$ with collection of urine, blood, and tissues for histopathology. All mice were killed humanely by a lethal dose of pentobarbital and exsanguination. 
Carnitine loading studies. Mice of both genotypes, 2 mo old, were given a single dose of $\mathrm{L}$-carnitine $100 \mathrm{mg} / \mathrm{kg}$ per os or no treatment and maintained on food and water for $10 \mathrm{~h}$. Mice were then killed humanely by a lethal dose of pentobarbital and exsanguination. At the end of the experiment, urine and blood were collected and quadriceps muscle was obtained and frozen in liquid nitrogen.

\section{RESULTS}

Urine organic acid analysis by gas chromatography-mass spectrometry showed a marked organic aciduria in the $\mathrm{J}$ mice compared to the normal pattern seen in the Y control mice (Fig. 1). The overall results indicate markedly increased concentrations [ $\overline{\mathrm{x}}$ (SD) $\mu \mathrm{mol} / \mathrm{mg}$ creatinine] of ethylmalonic 55.3 (90.2) and methylsuccinic acids 10.3 (18.3) and $N$-butyrylglycine $178(254)$ in nonfasting urine samples of six $\mathrm{J}$ mice; of these compounds only butyrylglycine in small amounts was detected in some control Y mice. This urine metabolite pattern would indicate a possible block in short-chain fatty acid oxidation. This was confirmed by enzymology of liver mitochondria, as described in Table 1. Overall butyryl-CoA dehydrogenation, which is catalyzed by both SCAD and MCAD, in the $\mathrm{J}$ mice averaged only $44 \%$ as compared to the Y control mice. By inhibiting MCAD activity with monospecific MCAD antiserum, the SCAD specific activity in the $\mathbf{J}$ mice is undetectable and heterozygotes have intermediate activity.

In the MCT challenge experiment, there were no clinical differences observed among the four groups. Results of that experiment (Table 2) showed that before the fasting period the $J$ mice $(n=4)$ had markedly elevated urinary concentrations of ethylmalonic acid, methylsuccinic acid, and $N$-butyrylglycine, compared to only a small amount of $N$-butyrylglycine detected in the control $\mathrm{Y}$ mice $(n=3)$. After the fasting period, with or without the MCT challenge, the Y controls had undetectable quantities of all three compounds, but the $\mathbf{J}$ mice had markedly elevated concentrations of ethylmalonic acid, methylsuccinic acid, and $N$-butyrylglycine. There were no major differences between the mutant mice groups whether or not they received MCT. The metabolite concentrations were lower in this experiment than in the random urines collected and analyzed from different mice described earlier. We currently do not understand the reason for this, except that urinary metabolites in general can vary widely in concentration. The serum glycine concentrations were significantly lower ( $p<0.025$ by Student's $t$-test) in the $\mathrm{J}$ mice comparing the like treatment groups (see Table 2). There were no differences in any other amino acid concentrations in any of the groups (data not shown). Also, there were no differences between the groups for serum glucose as a result of these treatments. Whether or not they received MCT oil, all J mice had fatty livers. This was confirmed by histopathology. No other lesions were seen, including examination of skeletal muscle.

In marked contrast, after an 18-h fast in a different experiment, the mean serum glucose value of the $J$ mice is $46 \%$ of the value of control mice (see Table 2). This is markedly different from the similar values seen among the four groups during the MCT experiment (10-h fast). By visual inspection, we also noticed friable, fatty livers in all the $\mathrm{J}$ mice, with normal-appearing livers in the $\mathrm{Y}$ controls after the fasting period. Histopathology demonstrated marked fatty change in the fasted $\mathbf{J}$ mice as compared to minimal changes seen in the controls (see Fig. 2).

In a final set of experiments, we examined the carnitine status of these mice, because human patients with the related disorders are often carnitine deficient $(1,4)$ when ill and excrete diagnostic acylcarnitines in their urine $(7,8,13-16)$ especially when dosed with carnitine. As shown in Table 3 , the $\mathrm{J}$ mice that received no carnitine, had slightly lower plasma and urine total carnitine. After the carnitine load, they excreted large amounts of butyrylcarnitine (Fig. 3), which was detected in only trace amounts in

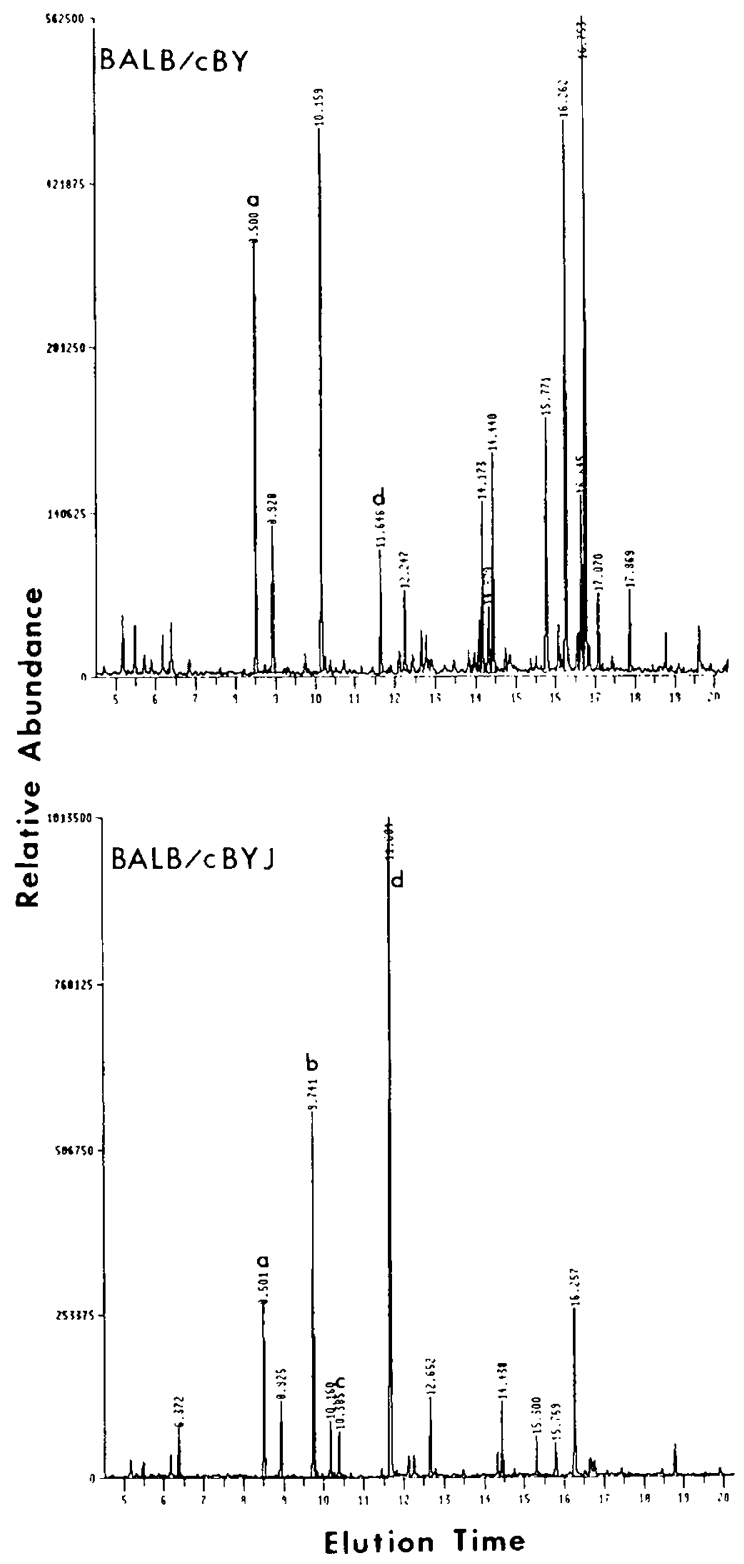

Fig. 1. Gas chromatography-mass spectrometry analysis of urine from a control $\mathrm{Y}$ mouse (top) and a mutant $\mathbf{J}$ mouse (bottom). Peaks identified here include $a$, internal standard-malonic acid; $b$, ethylmalonic acid, $c$, methylsuccinic acid, $d, N$-butyrylglycine. Note relative to the abundance of the internal standard $(a)$ the large peak of ethylmalonic $(b)$ and methylsuccinic acids $(c)$ in the affected $\mathrm{J}$ mouse, but absent in the control. Note also the large peak of $N$-butyrylglycine in the affected $\mathrm{J}$ mouse compared to the small peak in the control $Y$ mouse. These were nonfasting samples and are representative of results seen from the two genotypes.

the urine of the control group. Similarly, muscle carnitine analysis showed 9-fold higher concentrations of butyrylcarnitine in mutants than in the controls (see Table 3 ), which is significantly different $(p<0.005)$, by Student's $t$-test.

\section{DISCUSSION}

We have described and demonstrated SCAD deficiency in BALB/cByJ mice. Metabolically, SCAD is involved in dehydrogenation of short-chain $\left(\mathrm{C}_{4-6}\right)$ acyl-CoA in $\beta$-oxidation of fatty acids. When SCAD is deficient, abnormal metabolites accumulate. Ethylmalonic acid is probably produced from the intrami- 
Table 1. Mitochondrial Acyl-CoA dehydrogenase activity (pmol dichlorophenol indophenol reduced/min/mg protein)*

\begin{tabular}{|c|c|c|c|c|}
\hline \multirow{4}{*}{ Genotype } & \multicolumn{4}{|c|}{ Substrate } \\
\hline & \multicolumn{2}{|c|}{ Butyryl-CoA } & \multicolumn{2}{|c|}{ Octanoyl-CoA } \\
\hline & \multicolumn{2}{|c|}{ Additions } & \multicolumn{2}{|c|}{ Additions } \\
\hline & None & $\begin{array}{c}\text { MCAD } \\
\text { antiserum }\end{array}$ & None & $\begin{array}{c}\text { MCAD } \\
\text { antiserum }\end{array}$ \\
\hline$Y$ controls $(n=3)$ & $3,860(386)$ & $1,730(170)$ & $15,100(1,750)$ & 0 \\
\hline $\mathrm{Y} / \mathrm{J}$ heterozygotes $(n=3)$ & $2,670(246)$ & $872(310)$ & $12,500(2,740)$ & 0 \\
\hline$\%$ activity of control & 69 & 50 & 83 & \\
\hline $\mathrm{J}$ mutants $(n=3)$ & $1,690(388)$ & 0 & $12,300(1,640)$ & $328(284)$ \\
\hline$\%$ activity of control & 44 & 0 & 81 & \\
\hline
\end{tabular}

* The $\mathrm{Y}$ control mice are $\mathrm{BALB} / \mathrm{cBy}$, and the $\mathrm{J}$ mice with the marked organic aciduria are BALB/cByJ. Heterozygotes were produced by crossing a male $J$ with a female $Y$. The mice analyzed here were 1 mo old, and mitochondria were isolated from the liver. The antiserum used was rabbit anti-pig kidney MCAD and is added for preincubation with mitochondrial protein for $5 \mathrm{~min}$ at $37^{\circ} \mathrm{C}$ before substrates are added to start the reaction. Values given are mean and (SD).

Table 2. Medium-chain triglyceride challenge and fasting experiments*

\begin{tabular}{|c|c|c|c|c|c|}
\hline & \multicolumn{3}{|c|}{ Urinary organic acids ( $\mu \mathrm{mol} / \mathrm{mg}$ creatinine) } & \multirow{2}{*}{$\begin{array}{l}\text { Serum glycine } \\
(\mu \mathrm{mol} / \text { liter })\end{array}$} & \multirow{2}{*}{$\begin{array}{l}\text { Serum glucose } \\
\quad(\mathrm{mg} / \mathrm{dl})\end{array}$} \\
\hline & Ethylmalonic & Methylsuccinic & Butyrylglycine & & \\
\hline \multicolumn{6}{|l|}{ Pretreatment } \\
\hline$Y$ controls $(n=3)$ & ND & ND & $4.6(8.0)$ & & \\
\hline $\mathrm{J}$ mutants $(n=4)$ & $16.3(23.9)$ & $3.78(5.09)$ & $47.1(58.9)$ & & \\
\hline \multicolumn{6}{|l|}{ MCT + fast } \\
\hline$Y$ controls $(n=3)$ & ND & ND & ND & $465(115)$ & $153(40.4)$ \\
\hline J mutants $(n=3)$ & $17.0(2.10)$ & $5.40(1.35)$ & $57.4(14.3)$ & $305(13.9)$ & $183(35.1)$ \\
\hline \multicolumn{6}{|l|}{ Fast only } \\
\hline $\mathrm{Y}$ controls $(n=3)$ & ND & ND & ND & $484(116)$ & $183(55.1)$ \\
\hline $\mathrm{J}$ mutants $(n=3)$ & $18.2(12.2)$ & $5.74(2.93)$ & $62.9(33.5)$ & $309(18.2)$ & $177(45.1)$ \\
\hline \multicolumn{6}{|l|}{ 18-h fast only } \\
\hline $\mathrm{Y}$ controls $(n=6)$ & & & & & $151(33.9)$ \\
\hline $\mathrm{J}$ mutants $(n=3)$ & & & & & $69(8.3)$ \\
\hline
\end{tabular}

* All mice were 2 mo old, both sexes were tested. Medium-chain triglyceride oil was given per os at $150 \mathrm{mg} / \mathrm{kg} / \mathrm{dose}$, given three times every $4 \mathrm{~h}$, and the final samples were collected $2 \mathrm{~h}$ after the last dose. The mice were fasted for $10 \mathrm{~h}$. In all the samples analyzed, a trace of adipic acid was detected in 2 SCAD-deficient mice, none in any of the controls, and no suberic, sebacic, 3-hydroxybutyric, or glutaric acids were detected in any of the samples. In a different experiment, the mice were fasted only for $18 \mathrm{~h}$ and serum was coliected for glucose assay. All values given are mean and (SD). ND, none detected.

tochondrial accumulation of butyryl-CoA, which is carboxylated by propionyl-CoA carboxylase to form ethylmalonyl-CoA, then hydrolyzed to ethymalonic acid (17). $N$-butyrylglycine is formed by glycine conjugation of excess butyryl-CoA (18). Also, we have detected methylsuccinic acid in the urines of the SCAD-deficient mice, as found in the human patients. It is most likely generated from ethylmalonyl-CoA via formation of methylsuccinyl-CoA by methylmalonyl-CoA mutase (17). The recent finding of octanoylcarnitine $(7,14)$ and demonstrated MCAD deficiency in human cases of sudden infant death and Reye's syndromes implicates deficiency of MCAD and possibly the other acyl-CoA dehydrogenases in their pathogenesis.

The SCAD-deficient mice have many biochemical and pathologic features like those of the human patients described with SCAD deficiency and many similarities to the $\beta$-oxidation enzyme deficiencies in general. These mice have a marked ethylmalonic and methylsuccinic aciduria as described in the human patients, but in addition they have high concentrations of $\mathrm{N}$ butyrylglycine, not detected in some of the reported patients (3, 4). This is likely attributable to the well characterized differences between rodents and humans in glycine conjugation of various CoA derivative substrates, particularly butyryl-CoA (18). Rodents more readily produce butyrylglycine than primates for reasons that remain unclear. However, the production of buty- rylglycine as an alternative pathway to eliminate excess butyryl$\mathrm{CoA}$ is analogous to the production of suberylglycine and hexanoylglycine in MCAD deficiency (19) and isovalerylglycine in isovaleryl-CoA dehydrogenase deficiency (20) of humans. As discussed for isovaleric acidemia (20), glycine conjugation is a critical alternative pathway and is probably a major factor in determining the clinical severity of the disease. We hypothesize this may be an important mechanism to explain the relative resistance of these mice to acute clinical disease. We speculate the lower serum glycine in the mutant mice (as shown in Table 2) may result from the major urinary loss of butyrylglycine in the urine.

Additionally, these mice develop severe fatty liver and hypoglycemia upon prolonged fasting of $18 \mathrm{~h}$. Surprisingly, they remain clinically normal at this point. Another possible factor concerning the relative resistance to acute disease in the mice is that they have been maintained on standard rodent chow with a $5 \% \mathrm{wt} / \mathrm{wt}$ fat content, which is relatively low compared to the average growing child's diet. As demonstrated earlier, the mutant mice do not appear to have a systemic carnitine deficiency, although there was marked elevation of urinary and muscle butyrylcarnitine in the SCAD-deficient mice compared to controls. Overall, we believe this mouse model will be very useful to delineate several pathogenetic mechanisms of $\beta$-oxidation defi- 

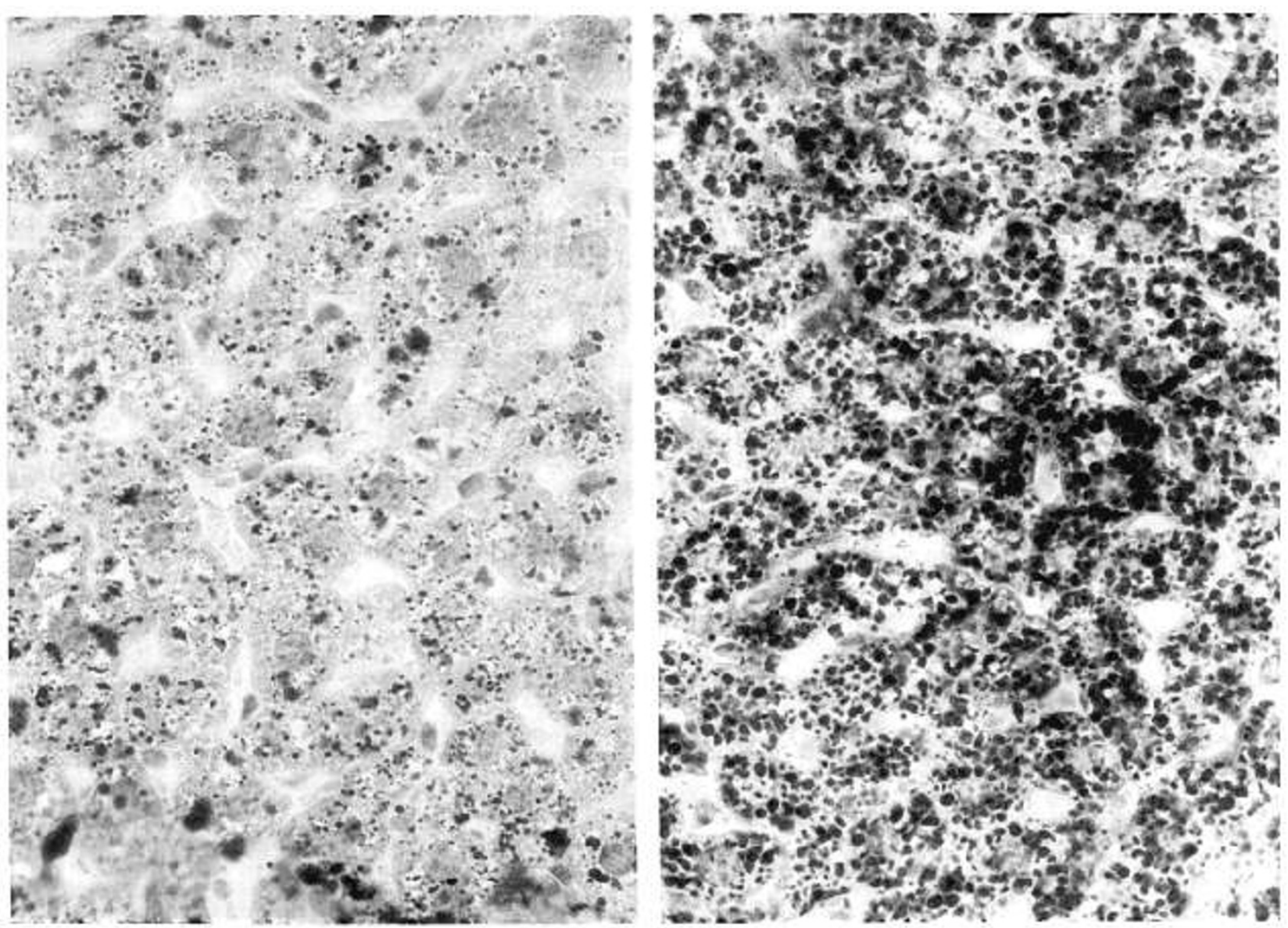

Fig. 2. Liver sections from a control $\mathrm{Y}$ (left) and $\mathbf{J}$ mutant mouse (right) were stained with oil-red-O, demonstrating the prominent fatty change in the mutant as compared to minimal changes in the control after an 18 -h fast.

Table 3. Carnitine analysis*

\begin{tabular}{|c|c|c|c|c|}
\hline & \multicolumn{2}{|c|}{ Y controls } & \multicolumn{2}{|c|}{$\mathrm{J}$ mutants } \\
\hline & No treatment & + Carnitine & No treatment & + Carnitine \\
\hline Plasma $(\mathrm{nmol} / \mathrm{ml})$ & $n=3$ & $n=3$ & $n=3$ & $n=3$ \\
\hline Free carnitinet & $31(14)$ & $47(19)$ & $16(5.0)$ & $36(4.0)$ \\
\hline Acylcarnitine & $44(10)$ & $80(28)$ & $44(11)$ & $100(19)$ \\
\hline Total carnitine & $75(23)$ & $130(46)$ & $56(16)$ & $140(23)$ \\
\hline \multicolumn{5}{|l|}{ Muscle (nmol/g wet wt) } \\
\hline Free carnitine $\dagger$ & $127(42.0)$ & $207(81.0)$ & $126(31.0)$ & $167(70.0)$ \\
\hline Acetylcarnitine $\ddagger$ & $114(14.0)$ & $119(12.0)$ & $92(11)$ & $93(9.0)$ \\
\hline Butyrylcarnitineł & $7(2)$ & $8(3)$ & $61(18)$ & $70(18)$ \\
\hline Free + acetyl + butyryl carnitines & $247(41.0)$ & $333(67.0)$ & $280(41.0)$ & $329(67.0)$ \\
\hline \multicolumn{5}{|l|}{ Urine ( $\mu \mathrm{mol} / \mathrm{mg}$ creatinine) } \\
\hline Free carnitine $\uparrow$ & $0.256(0.212)$ & $14.7(6.80)$ & $0.171(0.149)$ & $18.0(18.9)$ \\
\hline Acylcarnitine & $0.146(0.0211)$ & $17.4(5.70)$ & $0.083(0.088)$ & $27.4(29.2)$ \\
\hline Total carnitine & $0.401(0.231)$ & $32.1(9.05)$ & $0.254(0.123)$ & $45.4(48.2)$ \\
\hline
\end{tabular}

* Mice in this experiment were given no treatment or a single dose of $\mathrm{L}$-carnitine $(100 \mathrm{mg} / \mathrm{kg})$ per os. Blood, urine, and muscle samples were collected $10 \mathrm{~h}$ after treatment. Carnitines were assayed by $\dagger$ radioenzymatic assay or $\ddagger$ high-resolution fast-atom bombardment assay. Values given are mean and (SD).

ciency diseases, and it will be useful to understand the mechanisms of what appears presently to be a relative resistance to acute clinical disease in the mouse compared to humans. We speculate that the ability readily to glycine conjugate butyrylCoA and perhaps spare intramitochondrial carnitine concentrations may be important events protecting against acute disease. This mouse subline represents the only spontaneous animal model for any of the human $\beta$-oxidation enzyme deficiencies or organic acidemias, and it should be useful for investigating the metabolism, pathogenesis, and treatment of human disorders of $\beta$-oxidation and related diseases.

Acknowledgments. We thank Cathy Allshouse and Diane Gayle for technical assistance. 


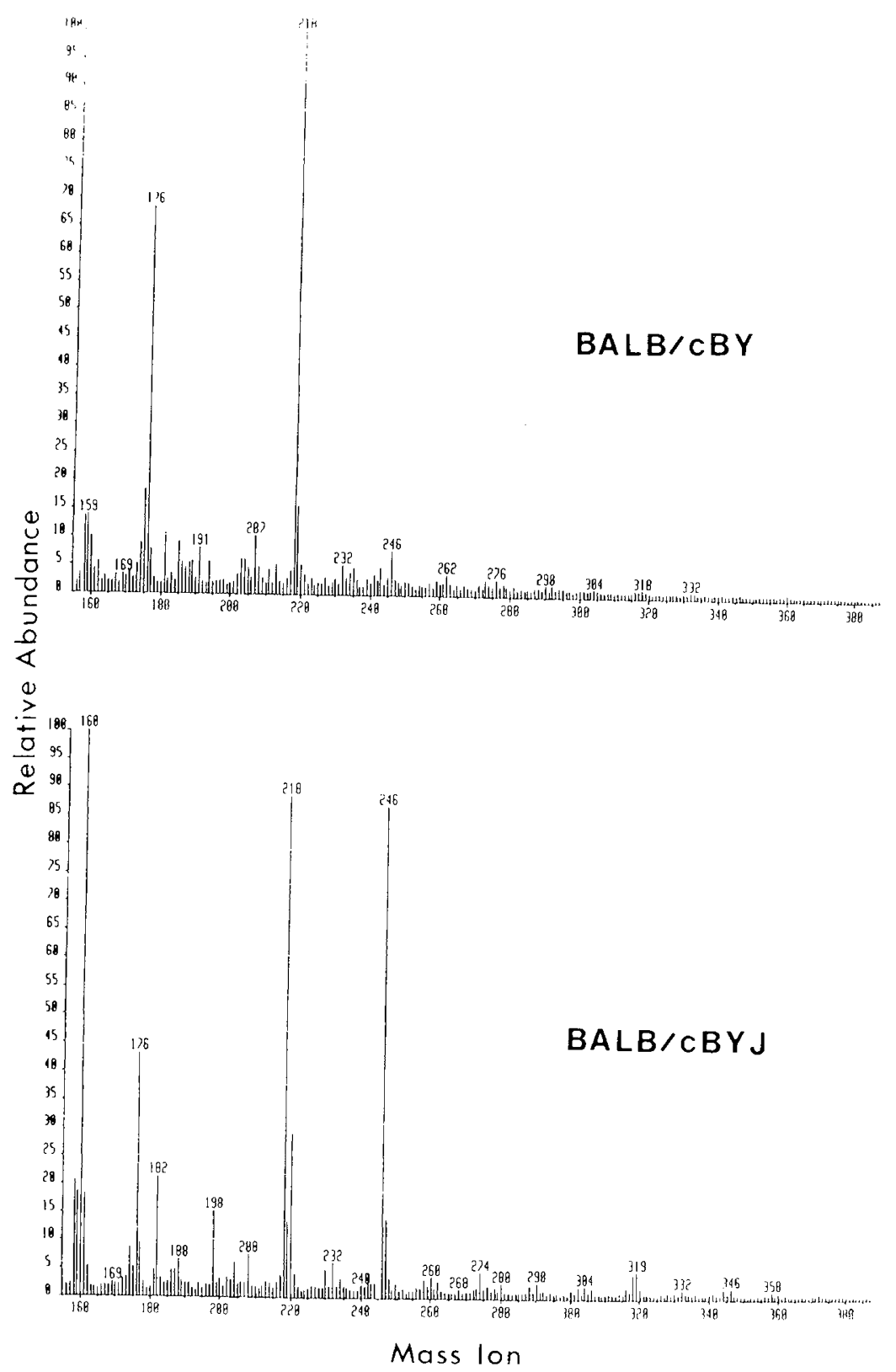

Fig. 3. Fast-atom bombardment-mass spectrometry (FAB-MS) analysis of urinary acylcarnitines. Examples shown are of a control Y mouse (top) and an affected $\mathbf{J}$ (bottom) mouse after an L-carnitine dose. Note prominent butyrylcarnitine peak (246) and $N$-butyrylglycine (160) peak in the affected mouse urine compared to the control. Free carnitine (176) and acetylcarnitine (218) are the expected normal acylcarnitines as seen in the control urine. Quantitative studies using FAB-MS, as illustrated above, on these mouse urines showed the following concentrations $(\mu \mathrm{mol} / \mathrm{mg}$ creatinine): controls $(n=2) N$-butyrylcarnitine $0.406-0.290$ and acetylcarnitine $(n=3) 11.3-22.5$; affected J mice $N$-butyrylcarnitine $(n=2) 0.967-$ 13.4 and acetylcarnitine $(n=2) 6.98-39.2$. The specific acylcarnitines described here are components of the total acylcarnitine value given in Table 3 .

\section{REFERENCES}

1. Turnbuli DM, Bartlett K, Stevens DL, Alberti KGMM, Gibson GJ, Johnson MA, McCullock AJ, Sherratt HS 1984 Short-chain acyl-CoA dehydrogenase deficiency associated with a lip storage myopathy and secondary carnitine deficiency. N Engl J Med 311:1233-1236

2. DiDonato SF, Cornelio F, Gellera C, Peluchetti D, Rimoldi M, Taroni F 1986 Short-chain acyl-CoA dehydrogenase-deficient myopathy with secondary carnitine deficiency. Muscle Nerve 9:178 (abstr)

3. Amendt BA, Greene C, Sweetman L, Cloherty J, Shih V, Moon A, Teel L, Rhead WJ 1987 Short-chain acyl-CoA dehydrogenase deficiency. J Clin Invest 79:1303-1309

4. Coates PM, Hale DE, Finocchiaro G, Tanaka K, Winter SC 1988 Genetic deficiency of short-chain acyl-coenzyme A dehydrogenase in cultured fibroblasts from a patient with muscle carnitine deficiency and severe muscular weakness. J. Clin Invest 81:171-175

5. Editorial 1986 Sudden infant death and inherited disorders of fat oxidation. Lancet 2:1073-1075
6. Duran M, Hofkamp M, Rhead WJ, Saudubray J-M, Wadman SK 1986 Sudden infant death and healthy affected family members with medium-chain acylcoenzyme A dehydrogenase deficiency. Pediatrics 78:1052-1057

7. Roe CR, Millington DS, Maltby DA, Wellman RB 1987 Post-mortem recognition of inherited metabolic disorders from specific acylcarnitines in tissue in cases of sudden infant death. Lancet 1:512

8. Chalmers RA, Roe CR, Stacey TE, Hoppel CL 1984 Urinary excretion of $L$ carnitine and acylcarnitines by patients with disorders of organic acid metabolism: evidence for secondary insufficiency of $L$-carnitine. Pediatr Res 18:1325-1328

9. Wood PA, Armstrong D, Sauls D, Davisson MT 1988 Screening mutant mice for inborn errors of metabolism. Lab Anim Sci 38:15-19

10. Prochazka M, Leiter EH 1986 A null activity variant found at the butyryl CoA dehydrogenase (Bcd-1) locus in BALB/cBy $J$ subline Mouse Newslett 75.31

11. Hyvarinen A, Nikkila EA 1962 Specific determination of blood glucose with o-toluidine. Clin Chim Acta 7:140-143

12. Johnson D, Lardy H 1967 Isolation of liver or kidney mitochondria. Methods Enzymol 10:94-96 
13. Roe CR, Millington DS, Maltby DA 1985 Diagnostic and therapeutic implications of acylcarnitine profiling in organic acidurias associated with carnitine insufficiency. In: Borum PR (ed) Clinical Aspects of Human Carnitine Deficiency. Pergamon, New York pp 97-107

14. Roe CR, Millington DS, Maltby DM, Kinnebrew P 1986 Recognition of medium-chain acyl-CoA dehydrogenase deficiency in asympatomatic siblings of children dying of sudden infant death or Reye-like syndromes. $J$ Pediatr 108:13-18

15. Millington DS 1986 New methods for the analysis of acylcarnitines and acylCoA compounds. In: Gaskell S (ed) Mass Spectrometry in Biomedical Research. Wiley, New York, pp 97-114

16. Millington DS, Roe CR, Maltby DA 1987 Characterization of new acylcarni- tines in patients with B-ketothiolase deficiency and glutaric aciduria type using mass spectrometry. Biomed Environ Mass Spectrom 14:711-716.

17. Mantagos S, Genel M, Tanaka K 1979 Ethymalonic-adipic aciduria, in vivo and in vitro studies indicating deficiency of activities of multiple acyl-Co $\mathrm{F}$ dehydrogenases. J Clin Invest 64:1580-1589

18. Kolvraa S, Gregersen N 1986 Acyl-CoA: glycine N-acyltransferase: organelk localization and affinity toward straight- and branched-chain acyl-CoA esters in rat liver. Biochem Med Met Biol 36:98-105

19. Vianey-Liaud C, Divry P, Gregersen N, Mathieu M 1987 The inborn errors of mitochondrial fatty acid oxidation. $J$ Inher Metab Dis 10:159-198

20. Krieger I, Tanaka K 1976 Therapeutic effects of glycine in isovaleric acidemia. Pediatr Res 10:25-29

\section{Announcement \\ THE ASSOCIATION OF MEDICAL SCHOOL PEDIATRIC DEPARTMENT CHAIRMEN, INC. \\ proudly announces the \\ Pediatric Scientist Training Program \\ 1988 Fellows}

Name

Markus Grompe, M.D.

Stuart J. Kahn, M.D.

Martin G. Martin, M.D.

James A. Newton, M.D.

Joseph W. St. Geme, III, M.D.

Craig L. Tendler, M.D.
Sponsoring Department and Chairman

University of Oregon, Portland

Robert C. Neerhout, M.D.

Washington University Herbert T. Abelson, M.D.

Harbor/UCLA

Delbert A. Fisher, M. D.

University of Utah Michael A. Simmons, M.D.

University of Pennsylvania Richard B. Johnston, Jr., M.D.

Mount Sinai School of Medicine Kurt Hirschhorn, M.D.

and gratefully acknowledges support and sponsorship for

National Institute of Child Health and Human Development

March of Dimes Birth Defects Foundation

St. Jude Children's Research Hospital

Cystic Fibrosis Foundation

William T. Grant Foundation

American Academy of Pediatrics 